and $73 \%(3147 / 4286)$ in those in category 7. Conversely, the proportions of pregnancies that resulted in termination were $50 \%(362 / 731)$ in women in deprivation category 1 and $14 \%$ $(602 / 4286)$ in those in category 7 . When planning health services to meet the needs of the population it is obviously essential to have information by deprivation category.

C BOULTON-JONES Health information scientist G MCILWAINE Consultant in public health (women's health) Department of Public Health, Greater Glasgow Health Board, Glasgow

K MCINNENY

Common Services Agency,

Information and Statistics Division

Edinburgh

1 McLoone P, Boddy FA. Deprivation and mortality in Scotland, 1981 and 1991. BMf 1994;309:1465-70.

\section{Inequalities in health}

\section{Are increasing ...}

EDIroR,-George Davey Smith and Jerry Morris point out the increasing inequalities in health in Britain. ${ }^{1}$ This issue is conspicuously absent from the Health of the Nation initiative.

In my annual report for 1991 I highlighted a difference of 10 years in the mean age at death between the most affluent and the most deprived wards in Coventry and the fact that in one ward over one third of male deaths occurred under the age of 65 , whereas in a more affluent ward the figure was less than one in six. The corresponding figures for female deaths were more than one in four and less than one in 10 respectively. As a result of this, in 1991 Coventry Health Authority adopted a local health target, which states: "By the year 2000 , the current differences in the mean age at death existing between the electoral wards in Coventry should be reduced by $10 \%$, based on a 3 year moving average."

In response to this target Coventry Health Authority, Coventry Family Health Services Authority, and Coventry City Council established a policy of specifically targeting resources at deprived areas in terms of health promotion, the development of primary health care, and service provision. Figures for 1990-2, published in my annual report for 1994, show that the gap in mean age at death has remained constant, although overall life expectancy has increased roughly equally in deprived and affluent wards.

There is nothing to stop individual health authorities developing local health targets reflecting inequalities in health in the absence of central government guidance on this subject.

KEITH WILLIAMS

Coventry Health Director of public health

Coventry CV1 2GQ

1 Davey Smith G, Morris J. Increasing inequalities in the health of the nation. $B M F$ 1994;309:1453-4. (3 December.)

\section{... or are they?}

EDrToR,-Although the statistics of health inequalities in Britain discussed in George Davey Smith and Jerry Morris's editorial' seem impressive, the absolute scale and nature of the problem, and what indeed is to be done to resolve it, remain elusive. Thus, working as a general practitioner in inner city London with a wide social mix of patients I find it difficult to relate, for example, the twofold differential in infant mortality between social classes I and V to clinical practice. Death in infancy is nowadays very rare and when it does occur, whether from the sudden infant death syndrome or childhood malignancy, it occurs just as often in professional households as working class households.

The discrepancy between the raw statistics of health inequalities and everyday experience is clarified by a closer examination of the causes of infant mortality (table), which confirms the twofold or $200 \%$ excess deaths between social class $\mathrm{V}$ and I. The overwhelming majority of infants, however, do survive the first year, and when the same data are presented as survival rates a slightly different picture emerges. Here the relevant figures for social class $I$ and $V$ are 994.4 and 988.8 per 1000 live births respectively, a survival advantage of only $0.6 \%$ for children born into professional families. The differential in infant mortality is accounted for predominantly by three major categories of disease-congenital anomalies, prematurity (including the respiratory distress syndrome), and the sudden infant death syndrome.

Infant mortality per 1000 legitimate live births, 1990

\begin{tabular}{lccc}
\hline & \multicolumn{3}{c}{ Social class } \\
\cline { 2 - 4 } & $\mathrm{I}$ & \multicolumn{1}{c}{$\mathrm{V}$} & Differential \\
\hline Total & 5.6 & 11.2 & \multicolumn{2}{c}{5.6} \\
$\begin{array}{c}\text { Congenital anomalies } \\
\begin{array}{c}\text { Prematurity and } \\
\text { respiratory distress } \\
\text { syndrome }\end{array}\end{array}$ & 0.9 & 2.0 & 1.1 \\
$\begin{array}{c}\text { Sudden infant death } \\
\text { syndrome }\end{array}$ & 1.9 & 3.6 & 1.7 \\
\hline
\end{tabular}

There are many causes of congenital anomalies including chromosomal and genetic abnormalities and intrauterine infections, but with the possible exception of folic acid supplementation for neural tube defects they are not readily amenable to prevention. The causes of prematurity are not known and again are not readily amenable to preventive intervention. By contrast, the sudden infant death syndrome is now recognised to be strongly influenced by sleeping position and has declined by $70 \%$ since the public health campaign advising that babies should sleep on their backs.

None of these three categories of disease is obviously related to poverty. So the vast edifice of argument about health inequalities mounted on the back of the twofold differential in infant mortality between the social classes is reduced to focusing on one truly preventable condition-the sudden infant death syndrome. Further, the actual excess in the number of deaths from this condition in social class $\mathrm{V}$ compared with social class I is only seven

Despite the vast literature on health inequalities generated over the past decade this type of detailed examination of the statistics has never been undertaken. Why might this be? The findings contradict the argument that the health differential between the social classes is readily attributable to "poverty" and also raises doubts about the proposed solutions -a major political programme of income redistribution. The Black report, for example, called for "greater restrictions on the amount of wealth which can be inherited, establishment of minimal -and maximal-earnings, the recognition of right to full employment and a major upgrading of child and family allowances." 3 There may well be good political arguments for such policies but it is hard to see how they could have much influence on the causes of the social class differential in infant mortality.

Mawbey Brough Health Centre,

JAMES LE FANU London SW8 2UD

1 Davey Smith G, Morris J. Increasing inequalities in the health of the nation. $B M 7$ 1994; 309:1453-4.

2 Office of Population Censuse and Surveys. Morrality statistics: prenatal and infant 1990. London: HMSO, 1991.

3 Townsend P, Davidson N. Inequalities in health - the Black report. London: Penguin, 1982

\section{Payment for blood donations in Germany}

EdrToR,-John D Cash, in his letter about proposed payment for blood donors in Germany, says that a statement made by me at the congress of the International Society of Blood Transfusion in Amsterdam in July had given the impression that the German government was planning to introduce a system of payment for all blood donors and that this payment would be DM50 $(£ 20)$ per donation.' This interpretation of my statement is wrong. What I said was: "In Germany it is considered acceptable for a regular donor to receive a global reimbursement of up to DM50. This has been recommended by the working group on blood. The federal government is of the same opinion and considers it to be in conformity with the recommendations of the Council of Europe."

This statement reflects the existing practice of reimbursing expenses in Germany. The introduction of a new system of reimbursing expenses is totally out of the question. Moreover, my statement makes it quite clear that a differentiated system of reimbursing expenses, which is allowed for in the recommendations of the Council of Europe, operates in Germany. According to these recommendations, reimbursing direct travel and real time expenses is admissible, and in Germany the maximum limit for such reimbursements is DM50. Consequently, the various blood and plasma donation services in Germany reimburse different sums of up to DM50; in some cases no reimbursements are paid at all.

There is absolutely no reason, therefore, for colleagues in the member states of the European Union and the Council of Europe to be concerned about the practice of reimbursing expenses in Germany. What is of decisive importance is the careful selection of donors, which is awarded particular importance in Germany and is subject to constant monitoring and further development. It is because of this that the prevalence and incidence of HIV infection in Germany are quite low.

The German government also expects to make considerable safety gains in the area of blood and blood products by achieving the goal of self sufficiency. The aim here is to become self sufficient in plasma and plasma products. This is a matter of great priority and it is being pursued energetically. Among other measures the German government is promoting the setting up and expansion of plasmapheresis centres with government funds. The government assumes that in a few years' time self sufficiency will have been achieved.

FRIEDGER VON AUER
Head of the division responsible for blood and blood products Federal Ministry for Health,

53108 Bonn,

Germany

1 Cash JD. Payment proposed for blood donations in Germany. $B M f$ 1994;309:1160. (29 October.)

\section{Measles campaign}

EDrToR,-Nigel Higson questions several aspects of the recent measles and rubella immunisation campaign and makes comments about the participation of general practitioners in further campaigns.' Already, good evidence shows that the campaign has been a considerable success. Coverage for the November phase is around $90 \%$; no district has reported $<80 \%$ and at least 12 have reported $\geqslant 95 \%$ coverage. More importantly, we are already able to see a considerable impact on notifications of measles; these are now about half the level before the campaign and are falling (figure).

The World Health Organisation now recommends measles campaigns for countries whatever 